\title{
A PRESENÇA DA LUSOFONIA NO ESPAÇO EPISTÉmiCo dAS Cî̂nCIAS dA COMUNiCAÇÃo: 10 ANOS DE ESTUDOS TEMÁTICOS
}

\author{
Anabela Gradim, Paulo Serra \& Valeriano Piñeiro-Naval
}

\begin{abstract}
RESUMO
Fazer a topologia das publicações de temática lusófona no campo das Ciências da Comunicação nos últimos 10 anos (2007-2017) permitiu caracterizar essa produção científica e constatar que esta vem aumentando, que é uma produção feminizada e essencialmente a duas vozes, onde Portugal e Brasil assumem um papel preponderante, que a bibliografia em Português é dominante, contrastando com o estado da citação na área em geral, e que, a partir das temáticas em foco, a Lusocom emerge como o grande think tank dos Estudos Lusófonos na área das Ciências da Comunicação. "A presença da lusofonia no espaço epistémico das Ciências da Comunicação" é um ensaio exploratório, descritivo, de abordagem quanti-qualitativa, com um universo que compreende as atas dos congressos da Sopcom, Ibercom, e o Anuário Internacional de Comunicação Lusófona editado pela Lusocom, num total de 3.252 artigos dos quais, atendendo à temática, foi selecionada uma amostra de 142 espécimes que constitui a base deste estudo.
\end{abstract}

\section{THE PRESENCE OF LUSOPHONY IN THE EPISTEMIC FIELD OF COMMUNiCATION SCIENCES: 10 YeARS OF THEMEd STUdies}

\begin{abstract}
Drawing up a survey of publications on lusophone themes in the field of Communication Sciences over the last 10 years (2007-2017) has made it possible to describe that scientific production and find that it has been increasing in volume. This scientific production is feminised and focuses on two voices, where Portugal and Brazil take on a predominant role, which contrasts with the state of citations in the field in general. Based on the themes examined, Lusocom emerges as the great think tank for Lusophone Studies in the Communication Sciences field. "The presence of Lusophony in the epistemic field of Communication Sciences" is an exploratory, descriptive study that takes a quantitative-qualitative approach, covering a sphere that comprises the conference proceedings of Sopcom, Ibercom and the Anuário Internacional de Comunicação Lusófona published by Lusocom. Of the total of 3.252 articles found, a sample of 142 were chosen, selected by theme, to form the basis for this study.
\end{abstract}




\section{LUSOFONIA(s)}

Mapear o campo dos Estudos Lusófonos no seu cruzamento com as Ciências da Comunicação é um desafio considerável que exige, desde logo, uma definição operativa de lusofonia.

Vítor de Sousa (2015) assinala a imprecisão do termo e traça-lhe uma genealogia assente no conceito de "portugalidade" do Estado Novo, de que o termo "lusofonia" seria a reconstrução pós-colonial. Maciel (2010, p. 101) considera-a "esfera de comunicação e compreensão, (...) acervo de memória cultural assente na partilha da língua comum", e comunidade em construção reinventada à luz do encontro entre culturas, que se expressa em modalidades individuais e práticas diversas.

Para Eduardo Lourenço lusofonia é "aquela esfera de comunicação e compreensão determinada pelo uso da língua portuguesa com a genealogia que a distingue entre outras línguas românicas e a memória cultural que, consciente ou inconscientemente, a ela se vincula" (Lourenço, 1999, p. 174). Não sendo apenas facto linguístico e fonético, o "continente imaterial disperso" da lusofonia remete para "um projeto, um sonho e, mesmo, uma assumida utopia" (Lourenço, 1999, p. 175), com configurações diferentes consoante o seu topos no espaço lusófono, sendo que, vista da Ibéria, "a lusofonia é, antes de tudo e eminentemente, a fantástica expansão e deriva de um falar que se constituiu como língua de vocação nacional e como cultura" (Lourenço, 1999, p. 177).

Também Moisés Martins fala da lusofonia como "continente imaterial" (Martins, Sousa \& Cabecinhas, 2006, p. 17) que "só poderá entender-se como espaço de cultura" e que "convoca hoje uma comunidade transnacional com propósitos político-culturais" (Martins, 2004, p. 12), "baseada numa língua comum, mas que transcende largamente a questão linguística” (Martins, 2004, p. 2) remetendo para um imaginário da pluralidade e da diferença que se expressa "em multiculturalismos com o denominador comum de uma mesma língua" (Martins, 2004, p. 12).

Helena Sousa, coordenadora do projecto "Lusocom: estudo das políticas de comunicação e discursos no espaço lusófono", resume bem a questão quando defende que "A Lusofonia é uma construção extraordinariamente difícil" por ser "um espaço geo-linguístico altamente fragmentado, um sentimento pleno de contradições, uma memória de um passado comum, uma cultura múltipla e uma tensa história partilhada" com um "património simbólico em permanente disputa" e "instituições cujos objectivos políticos são também eles próprios difusos e - não raramente - contraditórios e mesmo conflituosos" (Sousa, 2006a, p. 9).

Faraco (2012, p. 32), por seu turno, distingue o uso do termo lusofonia para fazer referência ao conjunto dos falantes do Português no mundo, "um uso descritivo, que recorta uma determinada quantidade e, aparentemente, não carrega maiores implicações políticas ou valorativas" de usos "marcados valorativa e politicamente" e que são objeto de infindáveis sentidos e complexa disputa.

Considerando o debate em curso, a profundidade semântico-ideológica do conceito e a diversidade de práticas que recobre, interessa-nos uma definição operativa de lusofonia que possa ser mobilizada na determinação dos estudos sobre a temática, e que se aproxime da aceção do termo como realidade linguística neutra. 
No Dicionário Houaiss da língua portuguesa lusofonia é fixada como "o conjunto daqueles que falam o português como língua materna ou não"; "conjunto de países que têm o português como língua oficial ou dominante" (Houaiss \& Villar, 2002, p. 2323). Para o Dicionário Houaiss a lusofonia abrange, além de Portugal, os países de colonização portuguesa, e ainda as variedades faladas por parte da população em regiões onde a presença portuguesa se fez sentir. Por essa razão, a sua riqueza, diversidade e multiplicidade territorial são extraordinárias, constituindo uma realidade cultural, política e geoestratégica de enorme valor.

A língua portuguesa é pluricontinental e policêntrica. Sendo a mesma língua, é falada e escrita de formas diferentes, correspondendo a histórias, patrimónios, vizinhanças linguísticas, estruturas gramaticais, pragmáticas, referências culturais e usos sociais diferentes. (...) é uma realidade dinâmica e multiforme. Todas as variantes dispõem de igual valor. Não há um 'centro' para a língua portuguesa, ela não possui só uma norma-padrão nem ninguém pode, sobre ela, invocar direitos especiais de propriedade. (Reto, Machado \& Esperança, 2016, p. 16)

Sendo a quarta língua materna mais falada do mundo, o Português, cuja partilha, na senda do Dicionário Houaiss, tomaremos como o traço caraterístico e distintivo da lusofonia, é a língua oficial de oito países - Angola, Brasil, Cabo Verde, Guiné Bissau, Moçambique, Portugal, São Tomé e Príncipe, e Timor Leste - cuja população excede, no conjunto, os 275 milhões de falantes, representando 3,7\% da população mundial (Reto et al., 2016, p. 61). Distribuída por quatro continentes, é "a única língua global sem fronteiras terrestres" (Reto et al., 2016, p. 61)'. É também a primeira língua mais falada no hemisfério sul, e em 2016-2017 reunia 200 mil estudantes estrangeiros em mais de 70 países, estimando-se que possa atingir os 390 milhões de falantes em meados do século, e os 487 milhões no final do século XXI (Reto et al., 2016, p. 57). Além da dimensão geoestratégica, é para todos os seus falantes um bem cultural e político, pátria e "continente imaginado" que desafia as tradicionais distinções entre Norte e Sul.

\section{Os Estudos Lusófonos no espaço das CiênCias da ComunicaÇÃo}

Este trabalho é uma pesquisa de carácter bibliográfico que tem por finalidade mapear a produção académica sobre as questões da lusofonia no campo das Ciências da Comunicação. Trata-se de um estudo exploratório, descritivo, com uma abordagem qualitativa e quantitativa que pretende contribuir para o conhecimento e clarificação do campo dos Estudos Lusófonos no âmbito da Comunicação. A pesquisa levanta e colige dados inéditos sobre uma década de estudos em Português na área, que representam o

\footnotetext{
' Registe-se ainda que a diáspora é responsável por mais 5,3 milhões de falantes nativos, com comunidades importantes em 22 países: EUA, Japão, Itália, França, Suíça, Alemanha, Reino Unido, Canadá, África do Sul, entre outros (Reto et al., 2016, p. 63). Há ainda seis crioulos de base portuguesa, desenvolvidos na sua maioria entre os séculos XVI e XVIII. Em África contam-se os crioulos da Alta Guiné e Golfo da Guiné; na India e Sri-Lanka os crioulos Indo-portugueses; na Ásia há crioulos de base portuguesa na Malásia e Indonésia; crioulos Sino-portugueses em Macau e Hong-Kong; e na América crioulos de influência portuguesa em Aruba, Curaçau, Bonaire e Suriname (Reto et al., 2016, p. 69).
} 
esforço de construção de uma comunidade e identidade lusófonas no seio das Ciências da Comunicação. Os resultados contribuem para uma reflexão mais documentada sobre o tema, possibilitando detetar a origem, extensão e sentido da produção científica do campo, o debate de ideias em curso, e as perspetivas, tensões e temáticas dominantes no processo de produção de saber nesta área.

Em sentido lato, Estudos Lusófonos são todos aqueles que se expressem em qualquer uma das variantes do Português. Neste estudo restringimos esse sentido para incluir apenas aqueles que tematizam, direta ou indiretamente, a lusofonia enquanto espaço político, linguístico, cultural, e de memória.

Para identificar o que consideraremos Estudos Lusófonos no espaço das Ciências da Comunicação, atentamos nas dimensões da lusofonia enquanto prática institucional, mas também na sua materialização aplicada, dando origem às seguintes seis categorias classificativas temáticas: artigos teóricos, instituições e políticas da lusofonia, políticas da língua, modalidades de expressão lusófona, identidade e alteridade nas comunidades lusófonas, e representações da lusofonia nos média.

A amostra compreende as atas do $V$ ao $X$ congresso da Sopcom - Associação Portuguesa de Ciências da Comunicação, num total de nove volumes²; os nove volumes do Anuário Internacional de Comunicação Lusófona, editado pela Federação Lusófona de Ciências da Comunicação33, e as atas dos congressos Ibercom de 2011, 2013, 2015 e 2017, publicadas pela Associação Ibero-Americana de Comunicação ${ }^{4}$. O conjunto, no período 2007-2017, entre atas e revistas, compreende 22 volumes, que perfazem um total de 3.252 artigos, dos quais, a partir das suas opções temáticas, foram recolhidos como representando estudos lusófonos 142 espécimes, ou seja, 4,4\% do total.

Esta amostra de 142 textos foi organizada numa base de dados em SPSS contemplando 10 variáveis de análise: título, ano de publicação, número e género dos autores, país da universidade do primeiro autor ${ }^{5}$, país tematizado, origem/fonte do trabalho, tipo, tema principal e secundário, e referências bibliográficas.

A recolha foi feita mediante observação qualitativa a partir da grelha de análise previamente determinada, descartando-se a pesquisa por palavras-chave, que produziria resultados menos finos. Assim, foram considerados todos os trabalhos que, mesmo não se avocando do conceito de "lusofonia", estudam, recompõem, estabelecem ou questionam essa identidade e comunidade em construção (Maciel, 2010), em conformidade com os seis eixos temáticos enunciados.

Nos seis temas que serviram de base à seleção e classificação da amostra, foram considerados artigos teóricos aqueles que se ocupam da clarificação de conceitos, de

\footnotetext{
${ }^{2}$ Ver https://www.sopcom.pt/page/eventos_cient_ficos\#congressos_sopcom

3 Ver http://www.intercom.org.br/lusocom/alusocom.shtml

${ }^{4}$ Ver http://www.assibercom.org/xvibercom2017/assibercom

${ }^{5}$ Relativamente à nacionalidade, verificou-se que este era o único dado passível de ser codificado objetivamente com base nas fontes disponíveis. A categoria esconde algumas limitações importantes para a interpretação dos resultados, como o facto de muitos destes estudos com origem em Portugal serem realizados por investigadores com origem em outros países Lusófonos, assumindo os estudantes brasileiros um peso significativo; e, também, que um mesmo autor pode ser codificado em países diversos ao longo da década em resultado de percursos académicos internacionais.
} 
instrumentos metodológicos, ou da conceptualização do campo; instituições e políticas da lusofonia, aqueles que em sentido lato as tomam por objeto, compreendendo variantes temáticas como a imigração, colonialismo, órgãos de comunicação social enquanto estruturas, e todas as considerações de política com impacto nas instituições da lusofonia, à exceção das que cabem na categoria seguinte; políticas da língua, compreendendo os que se dedicam às medidas explícitas e implícitas que regulam as práticas linguísticas da comunidade; modalidades de expressão lusófona, quando trabalham algum produto ou realização lusófona - seja simbólico, cultural, ou material; identidade e alteridade quando se ocupam da construção ou desconstrução desta nas comunidades lusófonas; e representações da lusofonia nos media para os trabalhos vocacionados para a análise de conteúdo ou análise crítica do discurso relativos a representações de conceitos, grupos, processos ou ideologias nos média.

A escolha dos dois mais importantes congressos de Ciências da Comunicação do espaço lusófono (Sopcom e Ibercom), e do anuário publicado pela Lusocom - Federação Lusófona de Ciências da Comunicação, que leva a efeito o "Congresso Internacional de Ciências da Comunicação dos Países de Língua Portuguesa", em 2018 na sua XIII edição ${ }^{6}$, considera que estas realizações, no espaço de uma década, remetem para o que de mais importante se está fazendo no campo, constituindo uma amostra mais extensa e compreensiva do que outro tipo de publicação, v.g. revistas académicas - já que nem todas as comunicações se materializarão nessa forma - e apresentando também a vantagem de permitir uma recolha mais centralizada do que a consideração de revistas, onde a grande variedade disponível induziria dispersão na amostra.

\section{Resultados}

Em termos quantitativos, a evolução da publicação entre 2007 e 2017 revela um aumento da produção científica consistente e sustentado, que se materializa numa curva de sentido ascendente, conforme o gráfico da Figura 1, onde os picos de publicação são consistentes com a bi-anualidade dos congressos da Sopcom e Ibercom.

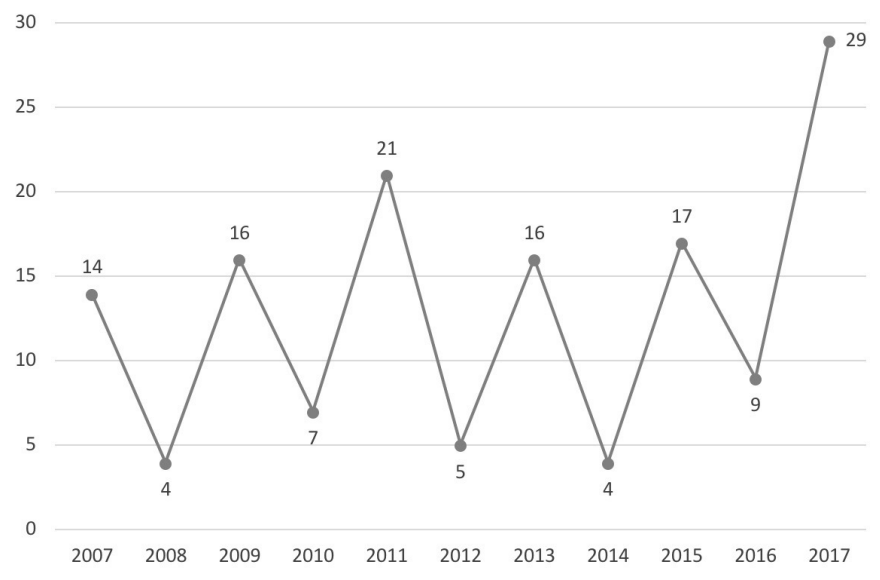

Figura 1: Timeline anual da evolução das publicações (número de trabalhos)

\footnotetext{
${ }_{6}^{6}$ Para um histórico dos 12 congressos da Lusocom realizados até à data, consultar http://www.lusocom.net/eventos/
} 
Em termos de autoria, $65 \%$ das publicações têm um autor $(n=93)$ e $35 \%$ foram realizadas em co-autoria $(n=49)$, dos quais $22 \%$ são trabalhos com dois autores. O conjunto corresponde a $87 \%$ das publicações, revelando que textos com três e mais autores são residuais.

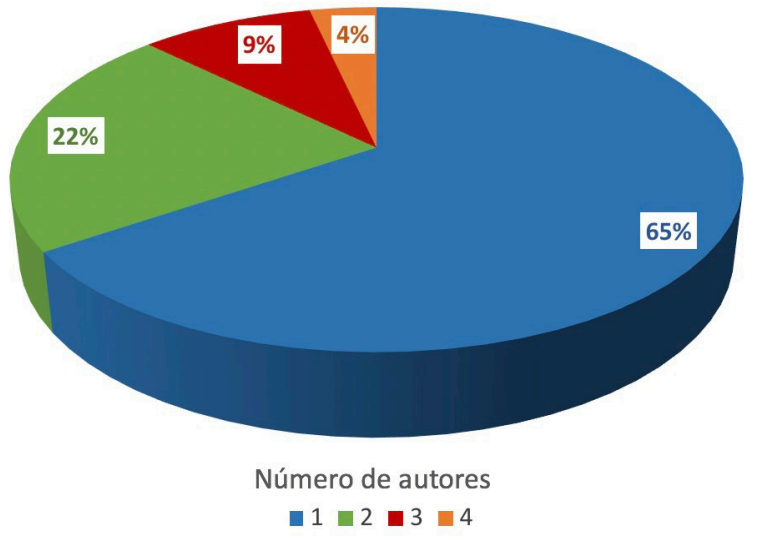

Figura 2: Percentagem de trabalhos de autor único e em co-autoria

Em termos de género, a produção científica na área é claramente feminizada, sendo as mulheres responsáveis por $57 \%$ da autoria $(n=81)$ e os homens por $43 \%(n=61)$, no caso dos primeiros autores.

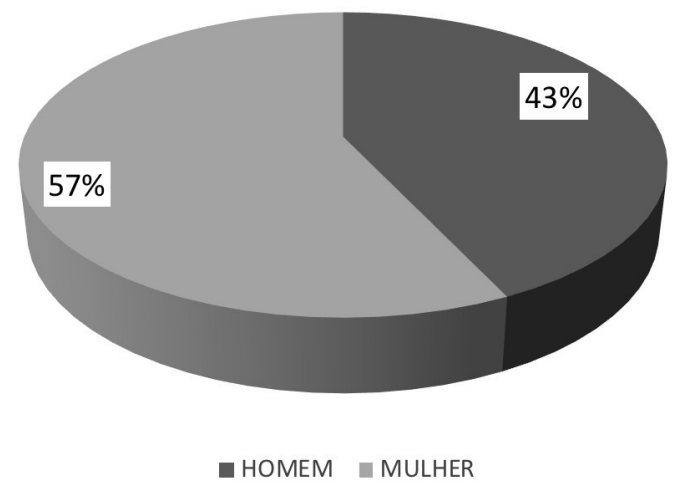

Figura 3: Percentagem de artigos por género dos autores

Esta divisão por género manifesta-se igualmente se considerarmos o conjunto sob o ponto de vista da quantidade da produção científica, registando-se três homens entre o conjunto dos nove autores que mais publicaram no universo considerado. Adicionalmente, no caso destes autores mais produtivos, tendo todos eles origem ou passagem pelo mesmo centro de investigação, o CECS - Centro de Estudos de Comunicação e Sociedade 7 , o conjunto expressa e revela a centralidade do referido centro para os Estudos Lusófonos no campo das Ciências da Comunicação.

\footnotetext{
7 Ver http://www.cecs.uminho.pt/
} 


\begin{tabular}{lccc}
\hline \multicolumn{1}{c}{ Nome } & Autoria & Coautoria & Total \\
\hline Lurdes Macedo & 4 & 1 & 5 \\
\hline Moisés de Lemos Martins & 3 & 2 & 5 \\
\hline Rosa Cabecinhas & 2 & 3 & 5 \\
\hline Michelly Santos de Carvalho & 4 & 0 & 4 \\
\hline Vítor de Sousa & 3 & 0 & 3 \\
\hline Isabel Macedo & 2 & 1 & 3 \\
\hline Madalena Oliveira & 2 & 1 & 3 \\
\hline Regina Pires de Brito & 2 & 1 & 3 \\
\hline Silvino Lopes Évora & 2 & 1 & 3 \\
\hline
\end{tabular}

Tabela 1: Autores/as que mais publicam (número de publicações)

Relativamente à universidade/centro de investigação de origem dos autores no momento da publicação, $62,7 \%(n=89)$ editaram estes trabalhos a partir de Portugal; $25,7 \%(n=36)$ fizeram-no a partir do Brasil; 8,5\% $(n=12)$ a partir da Galiza/Espanha; $1,4 \%$ desde Cabo Verde, e 2,1\% com origem em outros países.

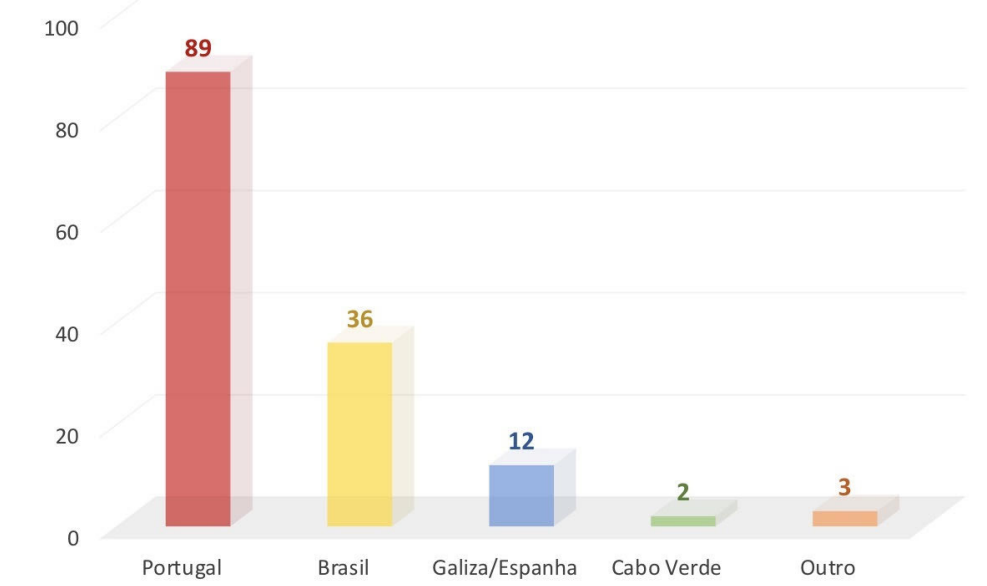

Figura 4: Número de publicaç̃es em função do país da universidade do primeiro autor

Os países tematizados no conjunto da amostra são, em primeiro lugar e em simultâneo Portugal e o Brasil, refletindo um conjunto muito alargado de trabalhos realizados numa perspetiva comparativa, e que são transversais a todos os seis temas considerados na classificação da amostra, cobrindo todo o espectro que vai dos trabalhos teóricos às representações mediáticas (31\%). Seguem-se os trabalhos que, focando a lusofonia em geral, foram considerados como tematizando o conjunto dos países lusófonos $(26,8 \%)$. Portugal é objeto de $21 \%$ dos estudos, o Brasil de 7,7\% e Angola e Cabo Verde são objeto de 3,5\% dos estudos cada um. Moçambique, São Tomé e Príncipe, Guiné Bissau e Timor apresentam valores abaixo de $3 \%$. Para a construção desta categoria foram considerados 
todos os países da CPLP, vindo posteriormente a verificar-se que a amostra também tematizava regiões não pertencentes à organização, nomeadamente Macau e a Galiza, que foram considerados concomitantemente na categoria Outros.

\begin{tabular}{lc}
\hline \multicolumn{1}{c}{ PAíses } & $\%$ \\
\hline Portugal e Brasil & 31,0 \\
\hline Todos países Lusófonos & 26,8 \\
\hline Portugal & 21,1 \\
\hline Brasil & 7,7 \\
\hline Angola & 3,5 \\
\hline Cabo Verde & 3,5 \\
\hline Outros & 2,8 \\
\hline Moçambique e São Tomé & 2,1 \\
\hline Guine Bissau & 0,7 \\
\hline Timor & 0,7 \\
\hline Total & 100 \\
\hline Tabela 2: Países tematizados no conjunto da amostra
\end{tabular}

Em temos de origem, 40,8\% dos trabalhos considerados provêm das atas dos congressos da Sopcom; 39,4\% têm a sua origem nos nove volumes do Anuário Internacional de Comunicação Lusófona publicados entre 2007 e 2017; e 19,7\% são trabalhos publicados nos quatro volumes de atas do Ibercom que foi possível recuperar referentes a este período.

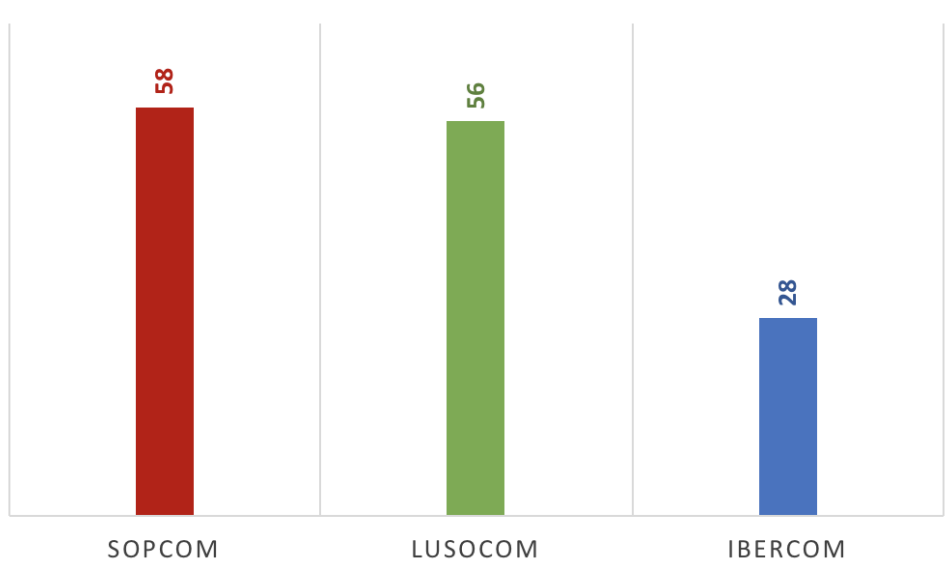

Figura 5: Número de trabalhos em função do evento de origem

Cada um dos trabalhos avaliados era potencialmente enquadrável em dois dos seis temas analisados, sendo uma minoria considerados mono-temáticos. Em relação aos temas principais e secundários, a Tabela 3 apresenta percentualmente a sua ocorrência, constatando-se que o tema principal mais frequente é o das instituições e políticas da 
lusofonia, e que o tema secundário mais frequente se refere às modalidades de expressão lusófona. Por seu turno o tema menos representado, quer como principal (10,6\%) quer como secundário $(6,3 \%)$ são as políticas da língua.

\begin{tabular}{lclc}
\hline \multicolumn{1}{c}{ TeMa PRINCIPAL } & $\%$ & \multicolumn{1}{c}{ TEMA SECUNDÁRIO } & $\%$ \\
\hline 1. Teórico & 12,0 & 1. Teórico & 13,4 \\
\hline 2. Instituições e políticas & 30,3 & 2. Instituições e políticas & 13,4 \\
\hline 3. Políticas da língua & 10,6 & 3. Políticas da língua & 6,3 \\
\hline 4. Expressão lusófona & 14,8 & 4. Expressão lusófona & 29,6 \\
\hline 5. Identidade e alteridade & 19,0 & 5. Identidade e alteridade & 13,4 \\
\hline 6. Representações mediáticas & 13,4 & 6. Representações mediáticas & 13,4 \\
\hline 7. Outro & 0 & 7. Outro & 4,2 \\
\hline Total & 100 & Total & 93,7 \\
\hline & Tabela 3: Temas principais e secundários dos trabalhos &
\end{tabular}

No que diz respeito aos temas, as três primeiras categorias (estudos teóricos, instituições e políticas) foram agrupadas considerando-se os trabalhos nestas categorias como estudos teóricos, e os trabalhos nas restantes (expressão lusófona, identidade, representações) como trabalhos aplicados. Esta recodificação da variável politómica em dicotómica teve por fim distinguir os estudos teóricos dos trabalhos aplicados ou práticos. Tomando como ponto de partida esta nova categoria, foram feitas algumas comparações, a primeira delas por género dos autores, a qual permite concluir que a maioria dos homens publica estudos teóricos, sendo responsáveis por $49 \%$ do total deste, e por apenas $35,8 \%$ do total de estudos aplicados; enquanto as mulheres são responsáveis por cerca de metade dos estudos teóricos, e por $64 \%$ dos aplicados.

\begin{tabular}{lccc}
\hline \multirow{2}{*}{ Género } & \multirow{2}{*}{ \% Total } & \multicolumn{2}{c}{ Macro Tema } \\
\cline { 3 - 4 } & & Teórico & Aplicado \\
\hline Masculino & 43,0 & 49,3 & 35,8 \\
\hline Feminino & 57,0 & 50,7 & 64,2 \\
\hline $\mathrm{n}$ & 142 & 75 & 67 \\
\hline Tabela 4: Género dos autores dos trabalhos teóricos ou aplicados (\% coluna)
\end{tabular}

Em função dos dados da Tabela 4, observa-se que os homens tendem a realizar trabalhos de tipo teórico em maior medida que as mulheres, que centram os seus esforços em propostas mais práticas ou aplicadas. No entanto, estas diferenças não podem ser consideradas como estatisticamente significativas $\left[X^{2}(1, N=142)=2,637 ; p=0,104\right]$.

Além da comparação de macro tema dos trabalhos por género dos autores, também se considerou de interesse saber que tipo de publicação era mais frequente dependendo da sua origem: 


\begin{tabular}{llll}
\hline \multirow{2}{*}{ Origem } & \multirow{2}{*}{ \% Total } & \multicolumn{2}{c}{ MaCro Tema } \\
\cline { 3 - 4 } & & \multicolumn{1}{c}{ Teórico } & \multicolumn{1}{c}{ Aplicado } \\
\hline Sopcom & 40,8 & $33,3^{-}$ & $49,3^{+}$ \\
\hline Ibercom & 19,7 & 18,7 & 20,9 \\
\hline Lusocom & 39,4 & $48,0+$ & $29,9-$ \\
\hline $\mathrm{n}$ & 142 & 75 & 67 \\
\hline
\end{tabular}

Tabela 5: Origem dos trabalhos teóricos ou aplicados (\% coluna) -Valor estatisticamente menor (análise dos resíduos tipificados corrigidos) +Valor estatisticamente maior (análise dos resíduos tipificados corrigidos)

O cruzamento destes dados, expresso na Tabela 5, demonstra que a Sopcom publica em maior medida trabalhos de tipo aplicado, e que a Lusocom publica em maior medida trabalhos de tipo teórico. Estas diferenças relativamente à origem dos trabalhos são estatisticamente tendenciais $\left[\mathrm{X}^{2}(2, N=142)=5,241 ; p=0,073\right]$.

Quanto ao número de referências bibliográficas dos trabalhos, aquelas que são em português $(M=11,12$; $D P=8,16)$ superam as referências bibliográficas em outras línguas $(M=10,06 ; D P=8,82)$. Embora estas diferenças não sejam estatisticamente significativas $[t(116)=0,892 ; p=0,374]$, o facto de os Estudos Lusófonos no campo das Ciências da Comunicação terem uma média de referências bibliográficas de autores lusófonos de 11,12 , que ultrapassa a média de referências de autores com outras origens e línguas $(10,06)$ contrasta vivamente com a mesma média quando esta reflete a totalidade do campo (Serra, 2016), como veremos na discussão dos resultados.

\section{DisCUSSÃO DOS RESULTADOS E CONCLUSÕES}

Os resultados deste trabalho mostram que os Estudos Lusófonos vêm aumentando em termos quantitativos na última década, que a maioria dos autores de estudos aplicados ou práticos são do sexo feminino, que os estudos teóricos se concentram no Anuário Internacional de Comunicação Lusófona e que os autores do sexo masculino têm preferência pelas grandes questões teóricas. Por esta razão, a Lusocom emerge como o grande think tank dos Estudos Lusófonos na área das Ciências da Comunicação, uma área construída essencialmente a duas vozes, e onde Portugal e Brasil assumem um papel preponderante. Verifica-se ainda que a bibliografia em Português é dominante, ultrapassando em média a citação de autores de outras línguas, e contrastando com o estado da citação nas Ciências da Comunicação em geral; que têm origem em universidades portuguesas a maioria das publicações consideradas, ainda que os seus autores possam ser estudantes de outros países lusófonos; que o CECS concentra o conjunto de investigadores que mais publicam dentro desta área, e que os temas mais abordados são as instituições e políticas da lusofonia, seguidos das questões de identidade e representações mediáticas.

Estes resultados mostram como o papel das associações e congressos é fundamental na promoção da lusofonia, e confirmam o maior envolvimento de Portugal e do 
Brasil na área. Note-se que, dos 12 congressos da Lusocom realizados até ao momento, apenas dois não o foram em Portugal, no Brasil e na Galiza: um em Moçambique (V congresso, 2002) e outro em Cabo Verde (XII congresso, 2016) - sendo que em Portugal foram realizados 5, no Brasil 3 e na Galiza 2. Perspetiva-se, para 2018, a realização do XIII congresso da Lusocom em Moçambique, em que foi entretanto criada a Acicom - Associação Moçambicana de Ciências da Informação e da Comunicação, e que constitui, com a Mediacom - Associação Cabo-verdiana de Ciências da Comunicação, as duas associações de ciências de comunicação do espaço lusófono fora do eixo Portugal/Brasil/ Galiza.

Consideramos ainda muito significativo que nos Estudos Lusófonos a citação de autores que se expressam em português seja muito mais elevada do que nas Ciências da Comunicação em geral, onde a maioria dos autores lusófonos concentram as suas referências em autores anglófonos (Serra, 2016). Estudos recentes têm tematizado a relação entre a linguagem e as condições políticas e materiais do capitalismo neoliberal global (Flores \& Chaparro, 2017; Joseph, 2006), o legado do colonialismo na hegemonia da língua inglesa (Pennycook, 2017) e os problemas que os cientistas de países periféricos enfrentam na divulgação de ciência, observando que a indústria editorial académica é um dispositivo que também serve para estabelecer e manter a hegemonia intelectual ocidental em escala global (Canagarajah, 2002).

Toda a ciência, por mais matemática que seja, envolve sempre uma língua natural para se explicar e tornar público aquilo que explica. Que a língua natural das ciências seja hoje predominantemente o Inglês, isso deve-se, por um lado, à hegemonia económica, político-militar e mediático-cultural do mundo anglo-saxónico, com destaque para os EUA e, por outro lado, a um etnocentrismo anglófono que é ativamente aceite pelas próprias vítimas do mesmo. Lutar contra esse etnocentrismo implica, para cada uma das línguas naturais marginalizadas, e em particular para o Português, ganhar uma tal massa crítica em termos de investigação e de publicação que obrigue as grandes editoras de livros e revistas científicas à tradução para o Inglês - e não apenas do Inglês. Traduzir é precisamente isso: sair de uma certa "visão do mundo" (Humboldt, 1836/1988) para entrar numa outra, promover o diálogo entre diferentes visões do mundo, recusando a distinção entre centros e periferias.

O capitalismo científico, com os seus dispositivos de classificação e avaliação, policiamento linguístico e indústria editorial centrada em anglófonos é um sistema que vem acentuando as desigualdades entre áreas emergentes de diferentes culturas de pesquisa e publicação. As políticas linguísticas e lutas linguísticas, presentes na indústria editorial académica, têm um impacto considerável nessa repartição simbólica e material de recursos científicos (Gradim \& Piñero-Naval, no prelo ).

Como dirá Moisés Martins, "num tempo pós-colonial e globalizado, as opções linguísticas e culturais exprimem a luta pela ordenação simbólica do mundo" (Martins, 2015, p. 16). É assim que "uma língua apenas pode fazer valer a sua força pela informação e pelo conhecimento que veicula" o qual deverá manifestar-se "em termos literários e em termos científicos, culturais e artísticos", pelo que o combate linguístico deve 
manifestar-se na política editorial, cultural e científica, dos países que a falam (Martins, 2015, p. 16).

Assim, entre os aspetos positivos revelados por este trabalho conta-se o de que, para os Estudos Lusófonos, a questão da hetero-referência e do etnocentrismo, peça não despicienda do "combate linguístico" de que fala Moisés Martins, tem uma orientação favorável. Já no que respeita ao equilíbrio entre os diversos pólos da lusofonia, verifica-se que esta é uma construção ainda sobretudo a três vozes Portugal/Brasil/Galiza e que, mesmo em Portugal, se encontra muito concentrada no CECS da Universidade do Minho.

De entre as estratégias para melhorar e intensificar a participação dos outros países da CPLP nesta construção serão essenciais ações como a organização dos congressos da Lusocom em outros espaços que não Portugal, a Galiza e o Brasil (sempre que necessário, com o apoio destes), a criação e o desenvolvimento de associações de Ciências da Comunicação em todos os países da lusofonia em que elas ainda não existem, e o envolvimento dos investigadores dos diversos países em projetos educativos e de investigação comuns (Serra, 2017).

Este que é o primeiro estudo sobre o perfil dos Estudos Lusófonos na área epistémica das Ciências da Comunicação tem, como limitações, a natureza da amostra focada nos congressos da área - e a construção do indicador de medida, de natureza qualitativa. Mapeando o campo na área das Ciências da Comunicação, estudos futuros podem incluir o alargamento da amostra pela pesquisa de publicações em bases de dados como a Scielo, WoS e Scopus, determinando o campo epistémico da sua origem a partir das revistas em que surgem, o que permitiria perspetivar os estudos de lusofonia em Comunicação no concerto das outras áreas onde é realizado, e pela inclusão de uma janela temporal mais alargada, que não se limitasse à última década.

\section{REFERÊNCIAS}

Canagarajah, S. (2002). Reconstructing local knowledge. Journal of Language, Identity and Education, 1(4), 243-259. DOI: 10.1207/S15327701JLIEO104_1

Faraco, C. A. (2012). Lusofonia: utopia ou quimera? Língua, história e política. In T. Lobo, Z. Carneiro, J. Soledade, A. Almeida \& S. Ribeiro (Eds.), Rosae: linguística histórica, história das línguas e outras histórias (pp. 31-50). Salvador: EDUFBA.

Feytor Pinto, P. (2010). O essencial sobre política da língua. Lisboa: Imprensa Nacional Casa da Moeda.

Fiorin, J. L. (2009). Língua, discurso e política. Alea: Estudos Neolatinos, 11(1), 148-165. DOI: 10.1590/ S1517-106X2009000100012

Flores, N. \& Chaparro, S. (2017). What counts as language education policy? Developing a materialist Antiracist approach to language activism. Language Policy, 1-20. DOI: 10.1007/s10993-017-9433-7

Gradim, A. \& Piñeiro-Naval, V. (no prelo). Policies for Portuguese and Spanish: the world's second publication languages in Web of Science.

Houaiss, A. \& Villar, M. de S. (2002). Dicionário Houaiss da língua portuguesa. Elaborado no Instituto Antônio Houaiss de Lexicografia e Banco de Dados da Língua Portuguesa. Rio de Janeiro: Círculo de Leitores. 
Humboldt, W. (1836/1988). On language: on the diversity of human language construction and its influence on the mental development of the human species. Cambridge: Cambridge University Press.

Joseph, J. E. (2006). Language and politics. Edinburgh: Edinburgh University Press.

Lourenço, E. (1999). A Nau de Ícaro seguido de imagem e miragem de lusofonia. Lisboa: Gradiva.

Maciel, C. (2015). A construção da comunidade lusófona a partir do antigo centro: micro-comunidades e práticas da Lusofonia. Lisboa: Camões - Instituto da Cooeração e da Língua.

Martins, M. L. (2004). Lusofonia e luso-tropicalismo: equívocos e possibilidades de dois conceitos hiper-identitários. Conferência inaugural no X Congresso Brasileiro de Língua Portuguesa, Pontifícia Universidade Católica, São Paulo. Retirado de http://repositorium.sdum.uminho.pt/handle/1822/1075

Martins, M. L. (2012). Revistas científicas de Ciências da Comunicação em Portugal: da divulgação do conhecimento à afirmação do Português como língua de pensamento. Intercom: Revista Brasileira de Ciências da Comunicação, 35(1), 233-251. Retirado de http://www.scielo.br/pdf/interc/v35nı/12.pdf

Martins, M. L. (Ed.) (2015). Lusofonia e interculturalidade - promessa e travessia. V. N. Famalicão: Húmus.

Martins, M. L., Sousa, H. \& Cabecinhas, R. (Eds.) (2006). Comunicação e lusofonia: para uma abordagem crítica da cultura e dos media. Porto: Campo das Letras.

Pennycook, A. (2017). The cultural politics of English as an international language. Londres: Routledge.

Reto, L., Machado, F. L. \& Esperança, J. P. (2016). Novo atlas da língua portuguesa. Lisboa: Imprensa Nacional Casa da Moeda.

Serra, J. P. (2016). O (des)conhecimento recíproco dos investigadores ibero-americanos de Ciências da Comunicação. Revista Lusófona de Estudos Culturais, 3(2), 57-68. Retirado de http://www.rlec.pt/index. $\mathrm{php} / \mathrm{rlec} /$ article/view/115

Serra, J. P. (2017). A lusofonía como projeto em construção. Anuário Internacional de Comunicação Lusófona 2015-16: metodologias da pesquisa, cibercultura, regulação e cooperação, 1, 19-25.

Sousa, H. (2006a). Comunicação e lusofonia: do lugar acrítico ao lugar da procura. In M. L. Martins, H. Sousa \& R. Cabecinhas (Eds.), Comunicação e lusofonia: para uma abordagem crítica da cultura e dos media (pp. 9-14). Porto: Campo das Letras.

Sousa, H. (2006b). A mobilização do conceito de lusofonia: o caso dos canais internacionais da RTP. In M. L. Martins, H. Sousa \& R. Cabecinhas (Eds.), Comunicação e lusofonia: para uma abordagem crítica da cultura e dos media (pp. 165-182). Porto: Campo das Letras.

Sousa, V. M. (2015). Da 'portugalidade' à lusofonia. Vila Nova de Famalicão: Húmus.

\section{NOTAS BIOGRÁFICAS}

Anabela Gradim é licenciada em Filosofia pela Universidade do Porto, e mestre, doutora e agregada em Ciências da Comunicação pela Universidade da Beira Interior, onde se doutorou com a dissertação A dimensão comunicacional da semiótica de Peirce. Ensina Jornalismo, Comunicação e Metodologia na Faculdade de Artes e Letras da UBI, onde dirige o Doutoramento em Ciências da Comunicação. É investigadora do Labcom - Laboratório de Comunicação Online, coordenando o Grupo de Comunicação e Media. 
Os seus interesses de investigação prendem-se com o Jornalismo, a Comunicação de Ciência, a Semiótica, a Retórica e o interface destas disciplinas com a Cibercultura e os Novos Media.

Email: anabela.gradim@labcom.ubi.pt

Morada: Universidade da Beira Interior, Av. Marquês D'Ávila e Bolama, 6200-001 Covilhã

Paulo Serra é licenciado em Filosofia pela Faculdade de Letras de Lisboa e mestre, doutor e agregado em Ciências da Comunicação pela Universidade da Beira Interior (UBI). Nesta Universidade, é Professor Catedrático no Departamento de Comunicação e Artes e investigador na unidade de I\&D Labcom.IFP - Comunicação, Filosofia e Humanidades. Desempenha atualmente, na UBI, o cargo de coordenador científico do Labcom.IFP e, a nível nacional, o de Presidente da Associação Portuguesa de Ciências da Comunicação (Sopcom). É autor dos livros A informação como utopia (1998), Informação e sentido: o estatuto epistemológico da informação (2003) e Manual de teoria da Comunicação (2008), co-autor do livro Informação e persuasão na web (2009), organizador do livro Retórica e política (2015) e coorganizador de múltiplos livros, o último dos quais Televisão e novos meios (2017). Tem ainda vários capítulos de livros e artigos publicados em obras coletivas e revistas, nacionais e estrangeiras.

ORCID: https://orcid.org/oooo-0001-7821-3880

Email: pserra@ubi.pt

Morada: Universidade da Beira Interior, Av. Marquês D’Ávila e Bolama, 6200-001 Covilhã

Valeriano Piñeiro-Naval é licenciado em Publicidade e Relações Públicas (Universidade de Vigo) e em Comunicação Audiovisual (Universidade de Salamanca). Doutor Europeu em Comunicação Audiovisual, Revolução Tecnológica e Mudança Cultural na Universidade de Salamanca, é atualmente membro integrado da Unidade de I\&D LabCom.IFP - Comunicação, Filosofia e Humanidades da Universidade da Beira Interior, onde está a usufruir de uma bolsa nacional de pós-doutoramento da Fundação para a Ciência e Tecnologia (FCT) de Portugal.

ORCID: https://orcid.org/oooo-0001-9521-3364

Email:vale.naval@labcom.ubi.pt

Morada: Universidade da Beira Interior, Av. Marquês D’Ávila e Bolama, 6200-001 Covilhã

* Submetido: 15.05.2018

* Aceite: 12.07.2018 